$7^{\text {th }}$ EMES International Research Conference on Social Enterprise (line 7)

\title{
Potentialities and limitations of blockchain technologies in the governance of social enterprise collectives: the case of Smart Ibérica
}

\author{
by David Rozas ${ }^{1}$ (drozas@ucm.es) \& Silvia Díaz-Molina1 (dmolina@ucm.es)
}

Social Enterprise (SE) scholars have explored the complexity behind the governance of SE collectives, including polycentricity, high degrees of autonomy, decision-making processes not based on capital ownership and a strong participatory culture (e.g. Borzaga \& Defourny, 2004; Nyssens, 2007; Defourny et al., 2014). Parallelisms can be found between these characteristics and those from the studies on the governance of Commons-Based Peer Production (CBPP) collectives (e.g. Fuster Morell et al., 2016; Arvidsson et al., 2017; Rozas, 2017). Firstly, we identify connections between the governance of SE and previously studied CBPP collectives, focussing on the similar challenges faced by these two types of collectives when aiming to scale up their governance processes. Secondly, we discuss the potentialities and limitations of blockchain technologies - a distributed and append-only ledger which enables the implementation of novel properties at an infrastructural level in a fully decentralised manner to create conditions which may facilitate the scaling up of governance processes in SE collectives. Concretely: "How can blockchain technologies help to scale up the governance of SE collectives?"

For this analysis we draw on the work of the Nobel laureate economist Ostrom (1990), whose research showed that under certain conditions local communities of peers can govern the management and production of commons in sustainable manners, demystifying "The tragedy of the commons" (Hardin, 1968). As part of her work, she also identified a set of shared principles (Ostrom, 1990, pp. 82-102) which are commonly employed by these collectives when finding ways to scale up their governance processes. Drawing on Ostrom's principles, we explore the affordances of tokenisation, self-enforcement and formalisation of rules, autonomous automatisation, decentralisation of power over the infrastructure, transparentisation and codification of trust (Rozas et al., 2018) provided by blockchain technologies for governance of social systems. More specifically, we explore the case of the SE collective Smart Ibérica (Spain). Smart is a federal European mutuality-based non-profit organisation which aims to ensure the administrative and legal coverage of cultural and creative workers during periods of activity and unemployment (Nogales Muriel, 2017). The development of the Smart model in Spain is characterised by its significant growth: increasing membership from 64 members in 2013, the year of its initial formal creation, to 2,871 members in 2016 (Nogales Muriel, 2017; pp.133). Smart Ibérica offers, in this respect, a compelling scenario to explore the

\footnotetext{
${ }^{1}$ GRASIA research group of Complutense University of Madrid, Madrid, Spain.
} 
aforementioned affordances for the social construction of blockchain-based tools which help to scale up the governance of SE collectives.

Thus, this article aims to tackle the lack of empirical studies on the applications of blockchain technologies for self-organised forms of governance. It also contributes to the challenging of dominant market-driven and techno-determinist discourses (e.g Swan, 2015; Hayes, 2016) in the emergent literature on blockchain-based governance, by building on perspectives which rely neither on the logics of private markets, nor on the coercion of traditional centralised institutions (Atzori, 2015).

\section{References:}

- Arvidsson, A., Caliandro, A., Cossu, A., Deka, M., Gandini, A., Luise, V., \& Anselmi, G. (2017). Commons based peer production in the information economy (Report).

- Atzori, M. (2015). Blockchain Technology and Decentralized Governance: Is the State Still Necessary? Available at SSRN 2709713

- Borzaga, C., \& Defourny, J. (Eds.). (2004). The emergence of social enterprise (Vol. 4). Psychology Press.

- Defourny, J., Hulgård, L., \& Pestoff, V. (Eds.). (2014). Social enterprise and the third sector: Changing European landscapes in a comparative perspective. Routledge.

- Fuster Morell M., Salcedo J.L., \& Berlinguer M. (2016). Debate About the Concept of Value in Commons-Based Peer Production. In: Bagnoli F. et al. (eds) Internet Science. INSCI 2016. Lecture Notes in Computer Science, vol 9934. Springer, Cham

- Hayes, A. (2016). Decentralized Banking: Monetary Technocracy in the Digital Age. In P. Tasca, T. Aste, L. Pelizzon, \& N. Perony (Eds.), Banking Beyond Banks and Money (pp. 121-131). Cham: Springer International Publishing.

- Hardin, G. (1968). The tragedy of the commons. Science, 162(3859), 1243-1248.

- Nogales Muriel, R. (2017). Social transformation and social innovation in the field of culture: The case of the SMart model and its adaptation across Europe (Doctoral dissertation, University of Barcelona).

- Nyssens, M. (Ed.). (2007). Social enterprise: At the crossroads of market, public policies and civil society. Routledge.

- Ostrom, E. (1990). Governing the Commons: The Evolution of Institutions for Collective Action. Cambridge University Press.

- Rozas, D. (2017). Self-organisation in Commons-Based Peer Production. Drupal:" the drop is always moving" (Doctoral dissertation, University of Surrey).

- Rozas, D., Tenorio-Fornés, A., Díaz-Molina, S., \& Hassan, S. (2018). When Ostrom Meets Blockchain: Exploring the Potentials of Blockchain for Commons Governance. Available at SSRN 3272329.

- Swan, M. (2015). Blockchain: Blueprint for a New Economy. Sebastopol, CA, USA: O'Reilly. 